\title{
ROS-PIAS $\gamma$ cross talk channelizes ATM signaling from resistance to apoptosis during chemosensitization of resistant tumors
}

\author{
S Mohanty ${ }^{1}$, S Saha ${ }^{1}$, D Md S Hossain ${ }^{1}$, A Adhikary ${ }^{1}$, S Mukherjee ${ }^{1}$, A Manna ${ }^{1}$, S Chakraborty ${ }^{1}$, M Mazumdar ${ }^{1}$, P Ray $^{1}$, K Das $^{1}$, \\ J Chakraborty ${ }^{1}, \mathrm{G} \mathrm{Sa}^{1}$ and T Das ${ }^{*, 1}$
}

With the existing knowledge of ATM's role in therapeutic resistance, the present study aimed at identifying the molecular mechanisms that influence ATM to oscillate between chemoresistance and chemosensitivity. We observed that the redox status of tumors functions as a major determinant of ATM-dependent 'resistance-to-apoptosis' molecular switch. At a low reactive oxygen species (ROS) condition during genotoxic insult, the ATM/sumoylated-IKK $\gamma$ interaction induced NF $\kappa$ B activation that resisted JNK-mediated apoptosis, whereas increasing cellular ROS restored ATM/JNK apoptotic signaling. A search for the upstream missing link revealed that high ROS induces oxidation and ubiquitin-mediated degradation of PIAS $\gamma$, thereby disrupting PIAS $\gamma-\mathrm{IKK} \gamma$ cross talk, a pre-requisite for IKK $\gamma$ sumoylation and subsequent NF $\kappa$ B activation. Interruption in the PIAS $\gamma$-mediated resistance pathway channels ATM signaling toward ATM/JNK pro-death circuitry. These in vitro results also translated to sensitive and resistant tumor allograft mouse models in which low ROS-induced resistance was over-ruled in PIAS $\gamma$ knockout tumors, while its overexpression inhibited high ROS-dependent apoptotic cues. Cumulatively, our findings identified an unappreciated yet critical combinatorial function of cellular ROS and PIAS $\gamma$ in regulating ATM-mediated chemosensitization of resistant tumors. Thus, therapeutic strategies employing ROS upregulation to inhibit PIAS $\gamma$ during genotoxic therapy may, in future, help to eliminate the problems of NF $\kappa \mathrm{B}$-mediated tumor drug resistance.

Cell Death and Disease (2014) 5, e1021; doi:10.1038/cddis.2013.534; published online 23 January 2014

Subject Category: Cancer

Genotoxic stress-induced apoptotic cell death by chemotherapy remains the core of anticancer treatment. However, despite the tremendous strides made in the development of targeted anticancer therapies, emergence of resistance to genotoxic drugs is still a major obstacle in the successful management of resistant and aggressive tumors. ${ }^{1-3}$ Therefore, a profound investigation into the in-depth molecular mechanisms of drug resistance is essential and may hopefully translate into effective therapies that can flip the switch from drug resistance to susceptibility.

An insult to the cellular blue print by several anticancer drugs initiates an orchestrated response coordinated by sensor, transducer and effector proteins that detect the damage and activate either a repair mechanism or an apoptotic program in case of overwhelming damage. ${ }^{4} \mathrm{~A}$ key arbiter of the DNA damage pathway is the ataxia telangiectasia mutated $(\mathrm{Atm})$ gene, a member of the PI3K superfamily. ${ }^{5}$ The ATM-dependent pathway serves as an anticancer barrier that helps to delay or prevent cancer as well as induces apoptosis upon genotoxic damage. ${ }^{6,7}$ However, DNA damage activates not only the well-documented pathways of DNA repair and apoptosis but also major signaling pathways of chemoresistance. $^{8-10}$ Interestingly, in contrary to tumorpreventive functions of ATM, it has been proposed that ATM inhibition might provide a general strategy to sensitize tumors to the cytotoxic effects of DNA-damaging therapies by preventing the execution of critical survival programs. ${ }^{8}$ Supporting this view, primary cells from ataxia telangiectasia (A-T) patients, ATM-knockout mice and ATM-deficient tumors have been found to be hypersensitive to ionizing radiation (IR) and chemotherapy-induced DNA double-strand breaks. ${ }^{9,10}$ However, the dearth of information for the molecular basis of ATM's decision to optimize resistance or apoptosis may have necessarily contributed to the failure of reputed genotoxic therapies. Therefore, knowledge of molecular phenomena that governs the oscillation of ATM between resistance and apoptosis to finally activate one of them is pivotal in improving therapeutic responses in drug-resistant cancer cells.

Very recently, the role of oxidative stress in regulating the chemosensitivity of cancer cells has gained immense recognition. ${ }^{11}$ Experimental evidence supports the fact that reactive oxygen species (ROS) has an important role as

\footnotetext{
${ }^{1}$ Division of Molecular Medicine, Bose Institute, P-1/12 CIT Scheme VII M, Kolkata 700 054, India

${ }^{*}$ Corresponding author: T Das, Division of Molecular Medicine, Bose Institute, P-1/12 CIT Scheme VII M, Kolkata 700054 , India. Tel: +91 3325693257 ; Fax: +91 332355 3886; E-mail: tanya @jcbose.ac.in

Keywords: apoptosis; drug resistance; ROS; NF $\kappa$ B; IKK $\gamma ;$ PIAS $\gamma$

Abbreviations: ATM, ataxia telangiectasia mutated; DCFDA, dichlorofluoresceindiacetate; DN, dominant negative; EAC, Ehrlich ascites carcinoma; $\mathrm{H}_{2} \mathrm{O}_{2}$, hydrogen peroxide; IKK $\alpha / \beta / \gamma$, I kappa B kinase alpha/beta/gamma; JNK, jun amino terminal kinase; MKK4, mitogen-activated protein kinase kinase 4; MKP1, mitogen-activated protein kinase phosphatase 1; NAC, $N$-acetyl cysteine; $N F \kappa B$, nuclear factor kappa beta; NSCLC, non-small cell lung cancer; PARP, poly (ADP-ribose) polymerase; PBS, phosphate buffer saline; PIAS $\gamma$, protein inhibitor of activated STAT gamma; ROS, reactive oxygen species

Received 05.8.13; revised 24.10.13; accepted 12.11.13; Edited by H-U Simon
} 
signaling molecules in diverse physiological processes. ${ }^{12}$ Indeed, low levels of ROS have been linked to cellular proliferation and drug resistance, which provides an explanation for the pro-oxidant state invariably associated with the transformed phenotype. ${ }^{13,14}$ In fact, mild-to-moderate levels of ROS have often been found to trigger pro-survival responses in vitro by the activation of mitogen-activated protein kinases (MAPKs), thereby contributing to resistance against therapy ${ }^{15}$ In contrast, higher levels of ROS stimulated multiple death pathways, namely, typical and atypical apoptosis, necrosis and so on, thereby enhancing the therapeutic efficiency. ${ }^{16-19}$ Therefore, a novel approach in enhancing tumor cell sensitivity to genotoxic stress would be to favorably tailor the redox status of cancer cells to restrain resistance and to allow efficient execution of drug-dependent apoptosis.

Our studies with different resistant and sensitive tumor models strongly support the notion that cellular oxidative stress generated in response to genotoxic stimuli is a major factor that fine tunes the signals downstream of ATM to induce either apoptosis or resistance. Our results demonstrated that, in comparison with sensitive tumors, resistant tumor cells maintained low levels of cellular ROS, thereby surviving genotoxic insult via activation of the ATM-IKK $\gamma-\mathrm{NF} \kappa \mathrm{B}$ resistance pathway. However, ROS beyond a certain threshold, as produced by severe genotoxic stress, induced 'resistance to apoptosis' switchover by interruption of the ATM-IKK $\gamma$ molecular talk, inhibition of $\mathrm{NF}_{\kappa} \mathrm{B}$ and subsequent execution of the ATM-JNK apoptotic cascade. In-depth exploration into hitherto unexplored mechanisms revealed that oxidationmediated PIAS $\gamma$ degradation by high ROS intervened IKK $\gamma$ sumoylation and hence the ATM-IKK $\gamma$ association, which subsequently enabled execution of ATM-dependent chemosensitization. Thus, strategies employing ROS upregulation to inhibit PIAS $\gamma$ during genotoxic therapy may, in future, help to eliminate the problems of $\mathrm{NF}_{\kappa} \mathrm{B}$-mediated tumor drug resistance.

\section{Results}

ATM, upon genotoxic damage, functions as a binary switch in dictating survival versus apoptotic responses in chemoresistant cells. An effort to evaluate the chemosensitivity of different NSCLC cells revealed that A549 and $\mathrm{NClH} 1299$ were highly resistant to different genotoxic drugs such as cisplatin, doxorubicin and etoposide, as compared with $\mathrm{NCIH} 460$ (Figure 1a). Interestingly, higher doses of the same drugs were able to produce a pronounced apoptosis of $\sim 60 \%$ in these resistant cells (Figures $1 \mathrm{a}$ and $\mathrm{b}$ ). These findings, therefore, indicated that resistant cells A549 and
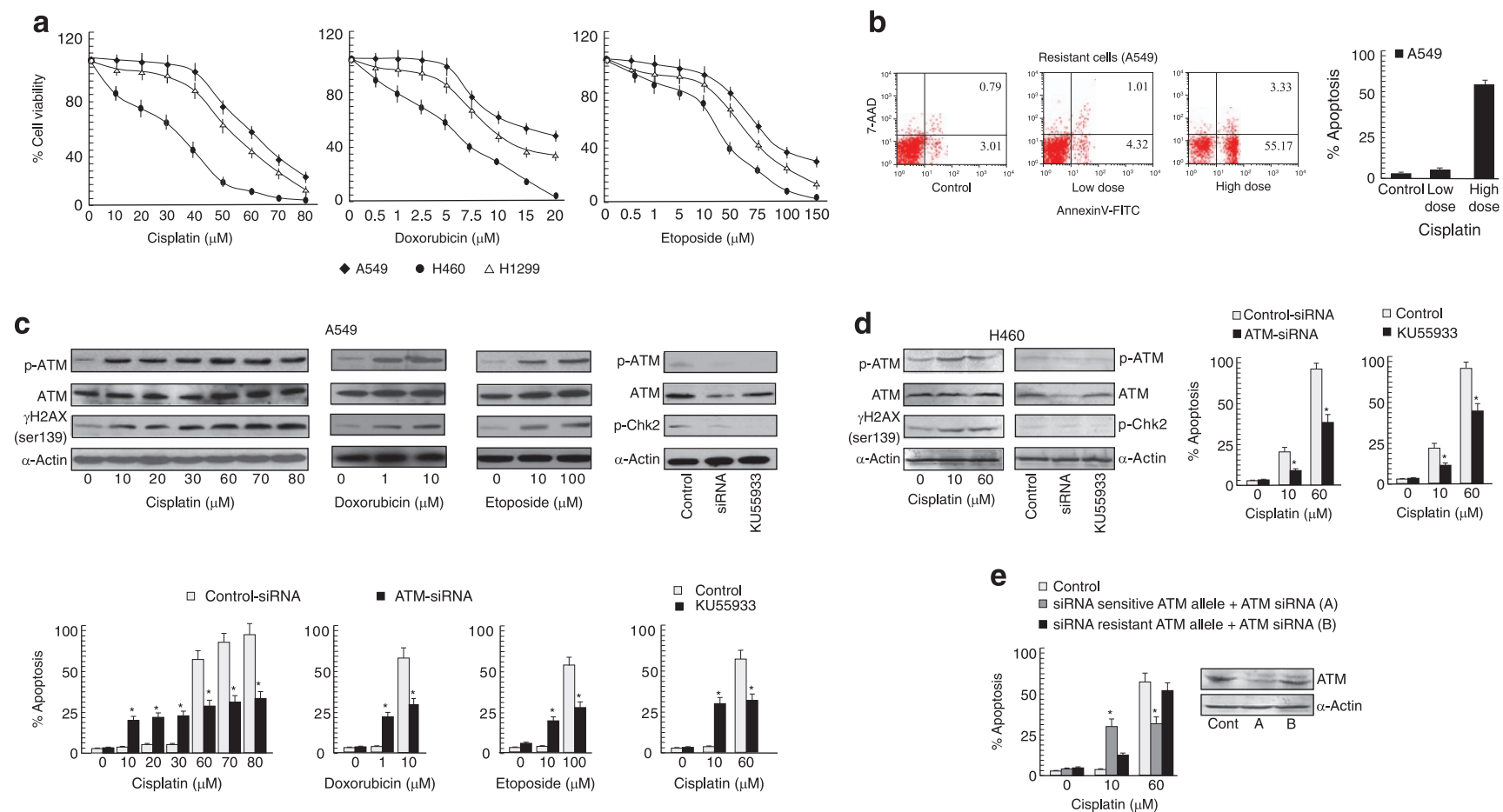

Figure 1 ATM is critical for both resistance and sensitivity responses of chemorefractory cells following genotoxic stress. (a) Percent viability of different cancer cells treated with dose range of genotoxic drugs, cisplatin, doxorubicin and etoposide, was scored by using trypan blue dye exclusion assay. (b) Genotoxic stress-induced apoptosis in resistant cancer cells was determined by quantifying the 7-AAD/Annexin-V-FITC-positive cells (regarded as apoptotic cells) flow cytometrically at low dose (10 $\mu \mathrm{M}$ ) and high dose $(60 \mu \mathrm{M})$ cisplatin (left panel) and represented graphically (right panel). (c) A549 and (d) H460 cells, treated with increasing dose of different drugs, were subjected to western blotting to determine the expression levels of p-ATM, ATM and $\gamma \mathrm{H} 2 \mathrm{AX}$. $\alpha$-Actin was used as internal loading control. Percent apoptosis in the ATM-siRNA transfected or KU55933 pre-exposed (c) A549 and (d) H460 cells was scored following drug treatment. The efficiencies of both genetic and pharmacological ATM depletion in (c) A549 and (d) $\mathrm{H} 460$ were determined by examining the expression status of p-ATM, ATM and p-Chk2. (e) Specificity of ATM knockdown was determined by scoring the percent apoptosis of siRNA-resistant ATM-cDNA- and siRNA-sensitive ATM-cDNA-expressing A549 cells transfected with ATM-siRNA following drug treatment. Values are mean \pm S.E.M. of five independent experiments in each case. ${ }^{*} P<0.01$ when compared with respective control sets 
$\mathrm{NClH} 1299$ were protected from genotoxic stress up to a certain limit, exceeding which turned on the apoptotic switch in these cells.

Consistent with the tumor-suppressive functions of ATM, ${ }^{5-7}$ we hypothesized that ATM activation might be a general strategy for chemosensitizing resistant tumors to the cytotoxic effects of DNA-damaging therapies. Interestingly, both resistant and sensitive NSCLC cells showed ATM phosphorylation and $\gamma \mathrm{H} 2 \mathrm{AX}$ induction over a wide-range of genotoxic doses (Figures 1c and d). As hypothesized, ATM silencing produced a survival benefit in both A549 (Figure 1c) and $\mathrm{H} 460$ (Figure 1d) cells at high dose cisplatin $(60 \mu \mathrm{M})$. In contrast, at low dose of cisplatin $(10 \mu \mathrm{M})$, unlike ATM-depleted $\mathrm{H} 460$ cells that manifested resistance (Figure 1d), ATM-silenced A549 cells underwent apoptosis (Figure 1c). Another sensitive breast cancer cell line, MCF-7, showed resistance to both low and high doses of different genotoxic drugs upon ATM silencing (Supplementary Figure 1). Consistent with cisplatin treatment, ATM-depleted A549 cells manifested profound sensitivity to low dose of doxorubicin and etoposide while being resistant to high doses of the drugs, suggesting that, apart from apoptotic functions at high dose of genotoxic stress, ATM might have a significant role in chemoresistance at low dose of the stress (Figure 1c). ATM-depletion results were further corroborated with an ATM-specific kinase inhibitor, KU55933 (Figures 1c and d). To confirm the specificity of the ATM knockdown, siRNA-resistant ATMcDNA was transfected in resistant cells. These cells, when engineered with ATM-siRNA, failed to exhibit chemosensitizing effect upon low doses of cisplatin exposure (Figure 1e). Levels of ATM, p-ATM and p-Chk2 (ATM substrate) were further examined to validate knockdown or inactivation of ATM function (Figures $1 c$ and $d$ ). These findings that ATM deficiency induces resistance at high dose, while causing apoptosis at low dose, confirm the central role of ATM as a binary switch that dictates exactly opposite tumor responses to varying degree of genotoxic stress in resistant cells.

ATM gears DNA damage responses in resistant cells toward NF BB-dependent survival or JNK-mediated apoptosis depending on the degree of genotoxic stress. In consistence with recent evidences about a critical function of $\mathrm{NF} \kappa \mathrm{B}$ in drug resistance, ${ }^{1,20}$ we observed that, unlike sensitive cells that manifested cytosolic retention of p65NF $\kappa \mathrm{B}$, resistant $\mathrm{A} 549$ cells displayed increased nuclear accumulation of $\mathrm{p} 65$ subunit of $\mathrm{NF} \kappa \mathrm{B}$ at low dose (Figure 2a). However, at high dose, which triggered apoptosis in resistant cells (Figures $1 \mathrm{a}$ and $\mathrm{b}$ ), localization of $\mathrm{NF} \kappa \mathrm{B}$ was essentially cytosolic, suggesting a role of $\mathrm{NF} \kappa \mathrm{B}$ in evading apoptosis. Our findings further demonstrated that overexpression of p65NF $\kappa \mathrm{B}$ (Figure $2 \mathrm{~b}$, upper right panel) rescued sensitive cells from apoptosis (Figure $2 \mathrm{~b}$, left panel); however, $1 \kappa \mathrm{B} \alpha$ super repressor $\left(I_{\kappa} \mathrm{B} \alpha-\mathrm{SR}\right)$ transfection (Figure $2 \mathrm{~b}$, upper right panel) restricted nuclear translocation of $\mathrm{p} 65 \mathrm{NF} \kappa \mathrm{B}$ (Figure 2b, lower right panel) in resistant cells, thereby inducing substantial apoptosis at low dose of cisplatin (Figure 2b, left panel). Interestingly, transfection of both $\mathrm{DN}-\mathrm{IKK} \beta$ and DN-IKK $\gamma$ but not DN-IKK $\alpha$ abolished low doseinduced resistance (Figure $2 \mathrm{c}$, upper panel) by restoring $\mathrm{I}_{\kappa} \mathrm{B} \alpha$ and inhibiting p65 nuclear translocation (Figure 2c, lower left panel). Further exploration revealed that compared with high dose, low dose induced $\mathrm{IKK} \gamma$ ubiquitination and $\mathrm{IKK} \beta$ phosphorylation (Figure 2c, lower right panel). These findings verified the role of both $\mathrm{IKK} \beta$ and $\mathrm{IKK} \gamma$ in the upstream of $N F \kappa B$ activation in the ATM-mediated resistance pathway.

With the IKK $\gamma-\mathrm{NF} \kappa \mathrm{B}$-dependent resistance at low dose, we next dissected the mechanism underlying the high doseinduced apoptosis in resistant cells. Our results showed hyperphosphorylation of JNK compared with p38MAPK in A549 cells treated with high dose (Figure 2d, upper left panel). Pharmacological inhibition and RNA interference (Figure 2d, lower panel) approaches revealed that inhibition of JNK relative to p38MAPK significantly blocked high dose-induced apoptosis (Figure 2d, upper right panel), thereby confirming the involvement of JNK in genotoxic chemotherapeutics such as cisplatin. Results presented in Figure $3 a$ further show that ATM depletion blocked low dose-induced IKK $\gamma$ ubiquitination, IKK $\beta$ phosphorylation and $\mathrm{p}^{2} 5 \mathrm{NF}_{\kappa} \mathrm{B}$ translocation to the nucleus on one hand and inhibited high dose-mediated JNK and caspase-3 activations on the other in A549 cells (Figure 3a). Cumulatively, our results suggest that, ATM, by regulating either the $\mathrm{IKK} \gamma$-dependent $\mathrm{p} 65 \mathrm{NF} \kappa \mathrm{B}$ pro-resistance pathway or the JNK-dependent functional pro-apoptotic pathway, is having a central role in deciding therapeutic efficiency of resistant tumors in response to the genotoxic drug.

Interestingly, both low dose and high dose of cisplatin induced phosphorylation of MKK4, the kinase responsible for JNK activation in an ATM-dependent manner (Figure 3b, upper left panel), although low dose failed to induce JNK phosphorylation (Figure 2d, upper left panel). Moreover, in MKK4-silenced A549 cells, high dose failed to induce apoptosis (Figure $3 \mathrm{~b}$, lower panel) concomitant with failure to activate the JNK-caspase-3 pathway (Figure 3b, upper right panel). It therefore can be hypothesized that, at both low dose and high dose, ATM could have induced resistant cell apoptosis through MKK4-mediated activation of JNK, which, however, was not evident at low dose. At this juncture, therefore, the possibility of the $\mathrm{p} 65 \mathrm{NF} \kappa \mathrm{B}$ pathway contributing to JNK inactivation during adaptive resistance was proposed. In support of this hypothesis, results in Figure 3c show that ATM-dependent JNK activation was possible at low dose only in the absence of functional p65NF $\kappa \mathrm{B}$, overexpression of which inhibited the same (Figure 3c). Interestingly, MKP1, which dephosphorylates $\mathrm{JNK}^{21}$ was induced at both mRNA and protein levels in low dose-exposed A549 cells (Figure 3d), whereas silencing MKP1 with specific MKP1-siRNA ensured low dose-induced JNK phosphorylation (Figure 3d). The inability of low dose to induce MKP1 in I $\kappa \mathrm{B} \alpha$-SR-expressing A549 cells (Figure $3 \mathrm{~d}$ ) further confirmed that $\mathrm{p} 65 \mathrm{NF}_{\kappa} \mathrm{B}$ inactivated JNK via MKP1 upregulation. These results clearly elucidate that, in chemoresistant cells, ATM upregulates MKP1 via p65NF $\kappa$ B to inhibit the ATM-induced JNK apoptotic pathway.

Degree of ROS dictates the choice of the downstream pathway. Next, our effort to understand the upstream mechanism that dictates the switchover of ATM signaling from the $\mathrm{NF}_{\kappa} \mathrm{B}$ pathway to the JNK pathway revealed that low dose cisplatin was unable to enhance ROS levels 
a

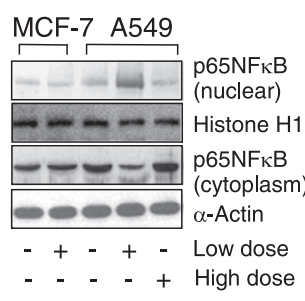

C

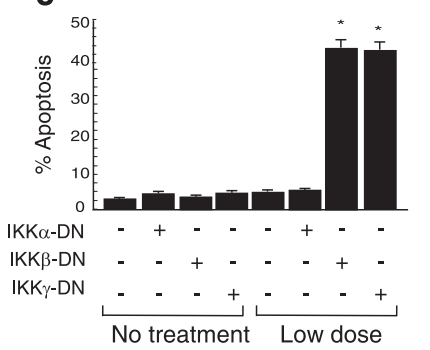

Co-ip:IKK $\gamma$ Probe:Ubiquitin

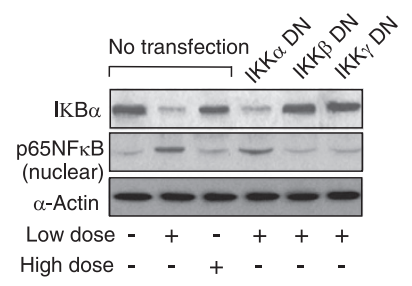

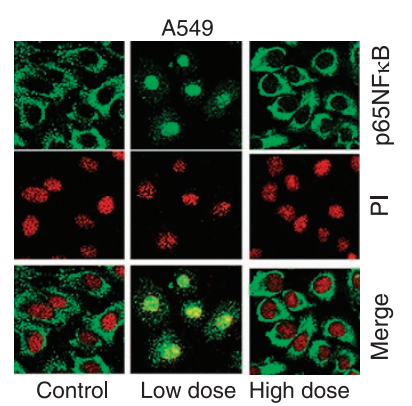

d
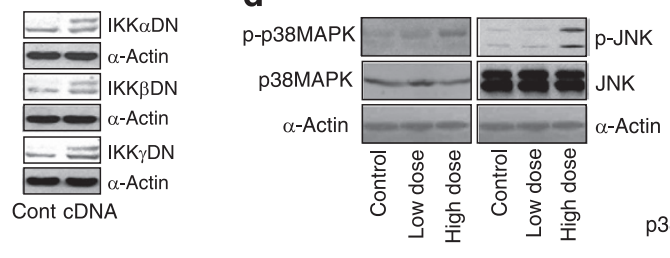

b

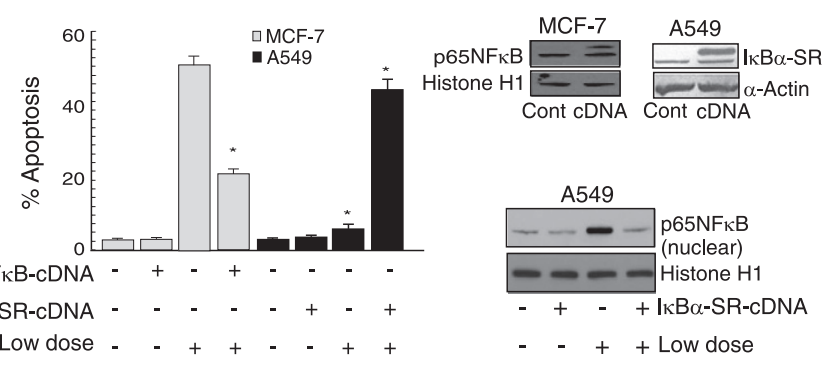

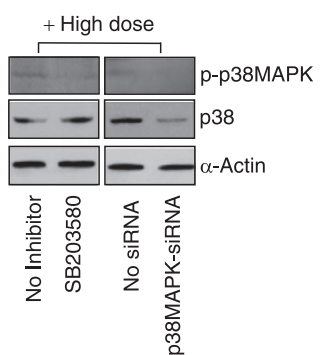
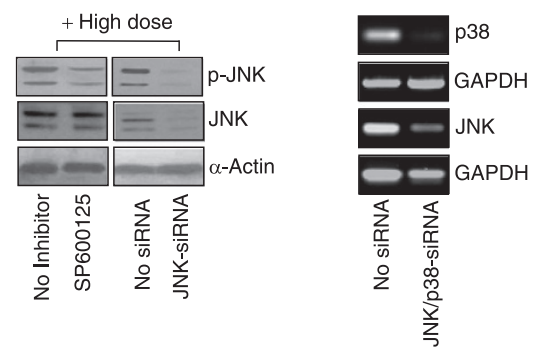

Figure 2 Inhibition of $\mathrm{NF} \kappa \mathrm{B}$ and concomitant activation of JNK during genotoxic stress are critical for inducing 'resistance to apoptosis' switchover in drug-resistant cancer cells. (a) Western blotting and confocal imaging experiments were conducted to determine nuclear translocation of p65NF $\kappa$ B in cisplatin-treated A549 and MCF-7 cells (b) Cisplatin-treated, p65NF $\kappa$ B-over-expressed MCF-7 cells and $I_{\kappa} \mathrm{B} \alpha$-SR-constituted A549 cells were subjected to flow cytometric determination of apoptosis (left panel). The effectiveness of transfecting $\mid \kappa B \alpha-S R-c D N A / p 65 N F \kappa B-c D N A$, respectively, to A549/MCF-7 cells was determined by western blot analysis (upper right panel). That $I_{\kappa} \mathrm{B} \alpha$-SR overexpression in $\mathrm{A} 549$ cells nullified cisplatin-induced $\mathrm{p} 65 \mathrm{NF} \kappa \mathrm{B}$ nuclear translocation was confirmed by western blotting (lower right panel). (c) The role of IKK $\alpha / \beta / \gamma$ in chemoresistance was evaluated by transfecting A549 cells with dominant negative (DN) clones of IKK $\alpha / \beta / \gamma$ followed by cisplatin treatment and subsequent flow cytometric determination of apoptosis. The efficacy of IKK $\alpha / \beta / \gamma$ DN transfections (upper panel; inset) as well as expression of $I_{\kappa} \mathrm{B} \alpha$ and nuclear p65NF $\kappa \mathrm{B}$ in un-transfected/transfected/ cisplatin-treated A549 cells (lower left panel) was determined by western blotting. Simultaneously co-immunoprecipitation experiment was employed to study the IKK $\gamma$ ubiquitination (Ub-IKK $\gamma$ ) in cisplatin-treated cells, and phospho-IKK $\beta(\mathrm{p}$-IKK $\beta$ ) expression was determined by western blot analysis in cisplatin-treated cells (lower right panel). (d) Un-transfected/p38MAPK/JNK-siRNA-transfected or SB203580/SP600125-pre-treated A549 cells were subjected to western blot analysis for determination of the levels of p38MAPK, p-p38MAPK, JNK and p-JNK in the presence or absence of cisplatin (upper left panel). In parallel, percent cell death was determined by Annexin-V/7-AADpositivity (upper right panel). The effectiveness of pharmacological and genetic interventions of p38MAPK and JNK was demonstrated both by western blot analysis and RT-PCR (lower panel). $\alpha$-Actin, histone H1 and GAPDH were used as internal controls. Values are mean \pm S.E.M. of five independent experiments in each case. ${ }^{*} P<0.01$ when compared with respective un-transfected/normal sets

significantly in resistant cells as compared with sensitive cells, although high dose induced significant ROS production (Figure 4a). In our next approach, external manipulation of ROS levels at low dose and high dose cisplatin using $\mathrm{H}_{2} \mathrm{O}_{2}$ $(4 \mathrm{mM} ; 1 \mathrm{~h}$ pre-treatment) and NAC $(40 \mathrm{mM} ; 12 \mathrm{~h}$ pretreatment), respectively, not only regulated drug responses (Figure $4 \mathrm{a}$ ) but also reversed the p-ATM-IKK $\gamma$ interaction status (Figures $4 \mathrm{~b}$ and $\mathrm{c}$ ), which has an important role in triggering $\mathrm{p} 65 \mathrm{NF} \kappa \mathrm{B}$ signaling in response to DNA strand breaks. ${ }^{11}$ To further strengthen our hypothesis that the p-ATMIKK $\gamma$ interaction status was subjective to ROS levels, resistant A549 cells were exposed to increasing doses of cisplatin $(0-80 \mu \mathrm{M} ; 1 \mathrm{~h})$ and $\mathrm{H}_{2} \mathrm{O}_{2}(0-20 \mathrm{mM} ; 1 \mathrm{~h})$ in independent experimental setups taking into consideration that the concentrations of $\mathrm{H}_{2} \mathrm{O}_{2}$ used strongly mimicked the amount of ROS produced at different doses of cisplatin (Figure 4e). Our results showed an inverse relation between the amount of ROS generated (Figure 4e) and the p-ATM-IKK $\gamma$ interaction status (Figure 4f, upper panel), IKK $\gamma$-dependent IKK $\beta$ phosphorylation (Figure 4d) and p65NF $\kappa$ B nuclear translocation (Figure 4f, lower panel). In contrast, increase in ROS induced JNK-mediated apoptosis in otherwise resistant A549 cells (Figure 4d). All these results signified that ATM, after being activated by DNA damage, functioned in concert with cellular redox status to differentially regulate the p-ATM-IKK $\gamma$ interaction and hence chemoresistance of malignant cells. 
a
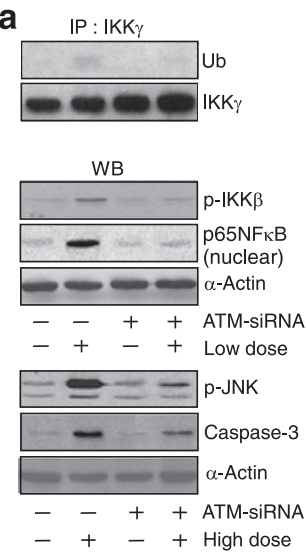

b

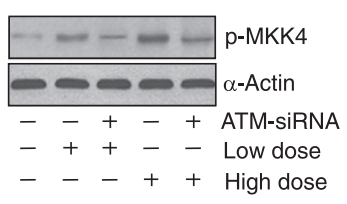

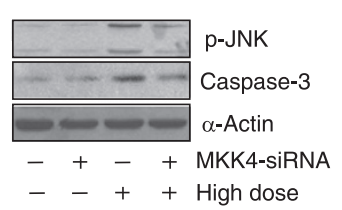

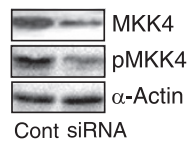

Cont siRNA

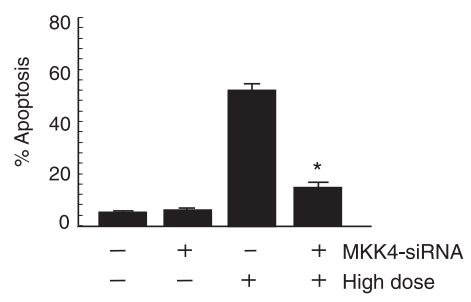

c

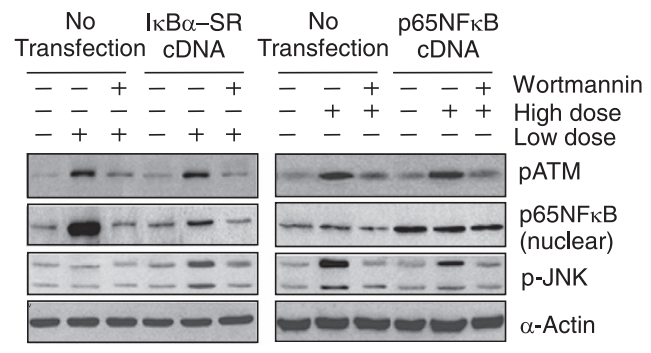

d
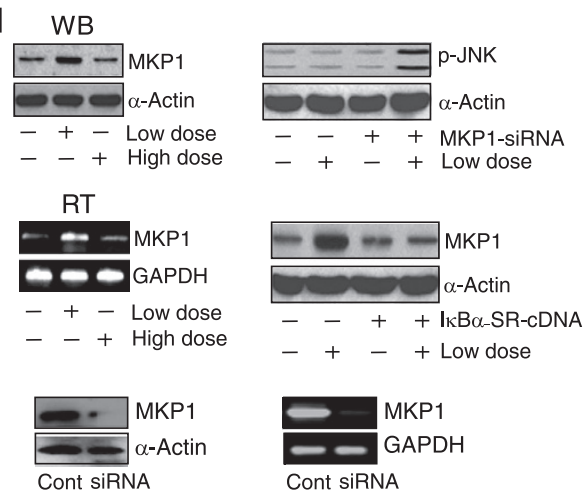

Figure 3 ATM in resistant cells steered DNA damage responses toward induction of NF $\kappa B$ or activation of JNK during low and high genotoxic stress, respectively. (a) Co-immunoprecipitation experiment was performed for determining the ubiquitination of IKK $\gamma$ in ATM-siRNA transfected A549 cells in presence of low dose of cisplatin (upper panel). In parallel, the western blotting technique was employed to determine $\mathrm{p}-\mathrm{IKK} \beta$, nuclear $\mathrm{p} 65 \mathrm{NF} \kappa \mathrm{B}$ (middle panel), and phospho-JNK and caspase-3 levels were determined in ATM-siRNA transfected A549 cells in presence of high dose of cisplatin (lower panel). (b) In the same experimental set, p-MKK4 was also analyzed (upper left panel). This was followed by transfection of A549 cells with MKK4-siRNA where changes in the expression levels of p-JNK and caspase-3 were verified (upper right panel). Simultaneously percent cell death was determined by Annexin-V-/7-AAD-positivity (lower left panel). The effectiveness of MKK4-silencing was confirmed by western blot analysis (lower right panel). (c) A549 cells transfected with the $\mathrm{I}_{\kappa} \mathrm{B} \alpha-\mathrm{SR}-/ \mathrm{p} 65 \mathrm{NF} \kappa \mathrm{B}-\mathrm{cDNA}$ were Wortmannin pre-treated before cisplatin treatment and were then analyzed for $\mathrm{p}-\mathrm{ATM}$, nuclear p65NF $K \mathrm{~B}$ and p-JNK by western blotting. (d) Protein and mRNA levels of MKP1 in untreated/cisplatin-treated A549 cells were determined by western blotting and RT-PCR experiments, respectively. At the same time, the p-JNK and MKP1 levels in MKP1-silenced cells and I $\kappa$ B $\alpha$-SR-overexpressed cells, respectively, were also determined. The efficacy of MKP1 knockdown was demonstrated both by western blot analysis and RT-PCR (lower panel). GAPDH and $\alpha$-actin were used as internal controls. Values are mean \pm S.E.M. of five independent experiments in each case. ${ }^{*} P<0.01$ when compared with respective untransfected/normal sets

Degradation of PIAS $\gamma$ at high ROS interrupted the ATM-IKK $\gamma$ cross talk resulting in chemosensitization of resistant cells. Our effort to explore the mechanism underlying the concentration-dependent effects of ROS revealed that, whereas PIAS $\gamma$ co-precipitated with $\mathrm{IKK} \gamma$ following exposure to lower dose range of cisplatin $(10-30 \mu \mathrm{M})$ or $\mathrm{H}_{2} \mathrm{O}_{2}(0.5-2 \mathrm{mM})$ (Figure $\left.5 \mathrm{a}\right)$, higher concentrations of the same compounds inhibited such an interaction (Figure 5a), thereby preventing $\mathrm{IKK} \gamma$ sumoylation (Figure $5 \mathrm{~b}$ ). Further exploration revealed that, although enhancing ROS at low dose cisplatin by exogenous $\mathrm{H}_{2} \mathrm{O}_{2}(4 \mathrm{mM})$ abridged the PIAS $\gamma$-IKK $\gamma$ molecular talk, quenching ROS at high dose cisplatin by NAC $(40 \mathrm{mM})$ favored IKK $\gamma$ sumoylation (Figures $5 a$ and $b)$. These results suggested that PIAS $\gamma$-mediated IKK $\gamma$ sumoylation is ROS dependent where low ROS favored the event while high ROS inhibiting the same, the underlying reason being extensive oxidation and subsequent ubiquitinmediated degradation of PIAS $\gamma$ at high ROS as generated by high dose of cisplatin (Figure $5 \mathrm{c}$, upper left panel). Degradation of PIAS $\gamma$ by high ROS and subsequent inhibition of IKK $\gamma$ sumoylation could, therefore, be the fundamental phenomenon in regulating ATM-dependent apoptosis or survival response. This hypothesis was further supported by our results showing that pre-exposure of a proteasome inhibitor MG132 blocked PIAS $\gamma$ degradation in resistant cells at high dose of cisplatin or high ROS conditions (Figure 5c, lower left panel). Furthermore, although PIAS $\gamma$ silencing inhibited $\mathrm{IKK} \gamma$ sumoylation, $\mathrm{NF} \kappa \mathrm{B}$ activation and globally sensitized resistant cells to low dose, PIAS $\gamma$-overexpression manifested $\mathrm{NF}_{\kappa} \mathrm{B}$ activation and hence resistance to high dose cisplatin (Figures 5d and e). Transfection of A549 cells with catalytically inactive PIAS $\gamma$ cDNA (PIAS $\gamma$ CA cDNA) impaired PIAS $\gamma$-dependent $N F_{\kappa} B$ activation and sensitized the transfectants (Figure $5 f$ ), thereby confirming that inhibition of PIAS $\gamma$ surmounts chemoresistance at low ROS.

To understand whether the contribution of ROS-PIAS $\gamma$ cross talk in determining the response of tumors to genotoxic therapy is specific for NSCLCs or global, that is, independent of the tissue of origin, different types of sensitive and resistant cell line pairs (MCF-7/DS-MCF-7 and Colo-205/HT-29) from 

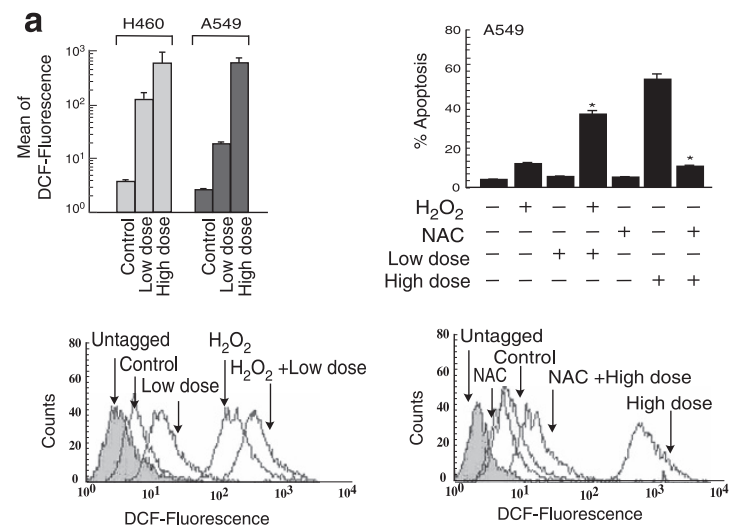

c

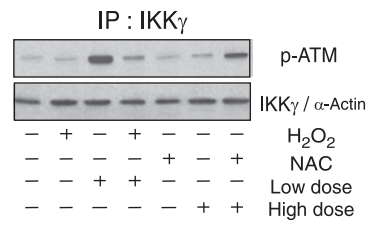

d

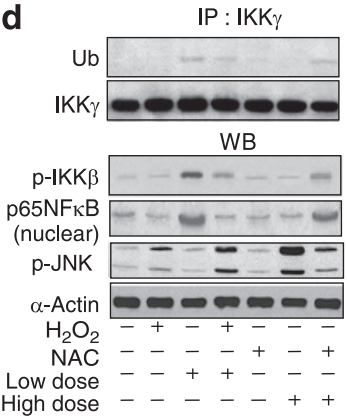

WB

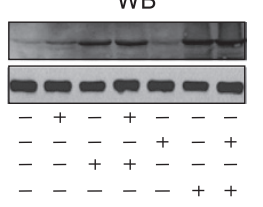

b

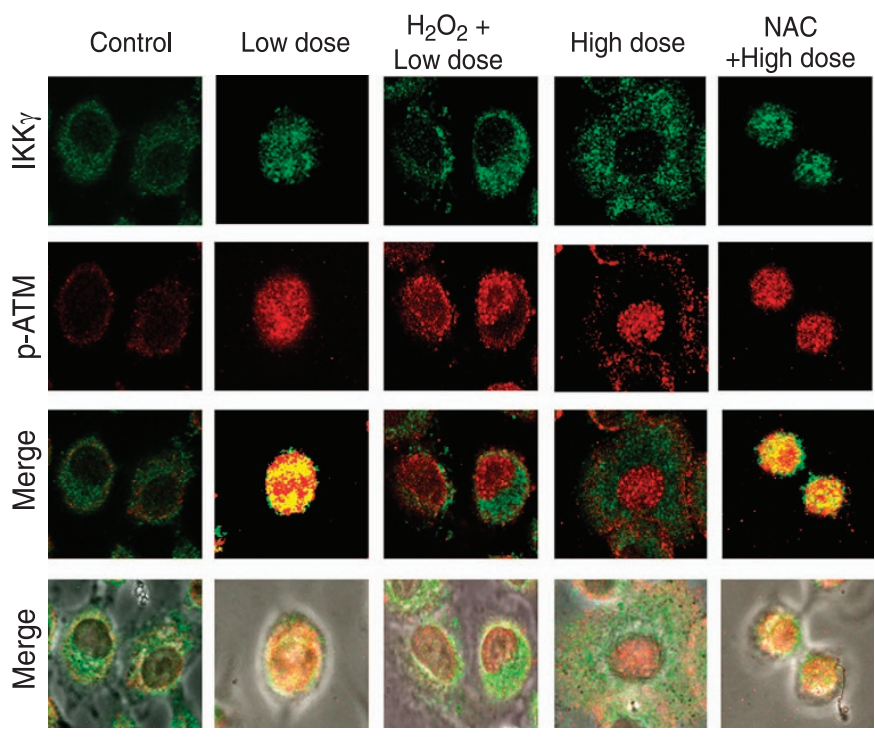

f

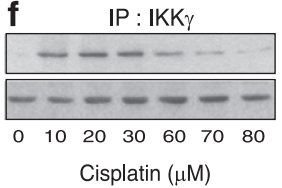

WB

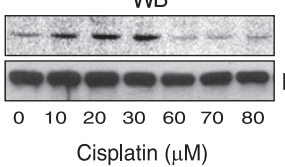

$\mathrm{IP}: \mathrm{IKK} \gamma$

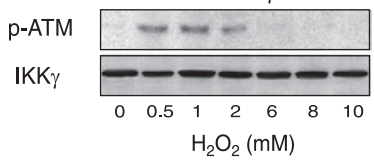

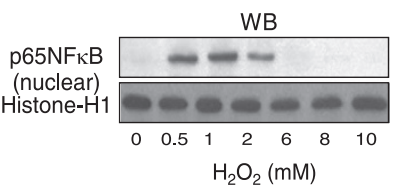

Figure 4 p-ATM and IKK $\gamma$ interaction and subsequent activation of $\mathrm{NF} \kappa \mathrm{B}$ or JNK response during genotoxic chemotherapy were largely determined by redox status of resistant cells. (a) Cisplatin-treated cancer cells were flow cytometrically assessed for determining the amount of ROS produced by increasing DCF-DA fluorescence. ROS dependence of apoptosis was validated in A549 cells pre-treated with $\mathrm{H}_{2} \mathrm{O}_{2} / \mathrm{NAC}$. The amount of ROS produced under these conditions was determined flow cytometrically. (b) The fact that IKK $\gamma / \mathrm{p}$-ATM nuclear co-localization was subject to ROS level modulation was further confirmed by confocal imaging. (c) A549 cells were preincubated with $\mathrm{H}_{2} \mathrm{O}_{2}(4 \mathrm{mM}, 1 \mathrm{~h}) / \mathrm{NAC}(40 \mathrm{mM}, 12 \mathrm{~h})$ followed by cisplatin treatment, and IKK $\gamma$ was immunopurified from cell lysates. The immunocomplex was then tested for IKK $\gamma$ associated $\mathrm{p}$-ATM by western blotting. In parallel, the levels of $\mathrm{p}$-ATM were determined by western blotting. (d) Co-immunoprecipitation experiments were employed to determine cisplatin-induced IKK $\gamma$ ubiquitination in $\mathrm{H}_{2} \mathrm{O}_{2} / \mathrm{NAC}$-pre-treated $\mathrm{A} 549$ cells. In the same experimental setup, the levels of $p$-IKK $\beta$, nuclear p65NF $\kappa B$, p-JNK were also determined by western blotting. (e) Cell viability and ROS production up on treatment of $\mathrm{A} 549$ cells with a dose range of cisplatin and $\mathrm{H}_{2} \mathrm{O}_{2}$-treated were scored by trypan blue dye exclusion assay and flow cytometrically by measuring DCFH-DA fluorescence, respectively. (f) IKK $\gamma$ precipitates and nuclear lysates of cisplatin-/ $\mathrm{H}_{2} \mathrm{O}_{2}$-treated $\mathrm{A} 549$ cells were subjected to western blotting to determine the amount of $\mathrm{p}-\mathrm{ATM}$ and nuclear $\mathrm{p} 65 \mathrm{NF} \kappa \mathrm{B}$, respectively. $\alpha$-actin and histone $\mathrm{H} 1$ were used as internal controls. Values are mean \pm S.E.M. of five independent experiments in each case. ${ }^{*} P<0.01$ when compared with respective control sets

different tissue sources were employed. Results depicted that cells resisting genotoxic therapy displayed low levels of intracellular ROS, whereas sensitive cells displayed significant increase in ROS under the same condition (Figures $5 \mathrm{~g}$ and $h$ ). In addition, manipulating ROS before drug treatment in DS-MCF-7 with ROS-inducer $\mathrm{H}_{2} \mathrm{O}_{2}$ considerably enhanced ROS levels (Figure 5i, left panel) and significantly chemosensitized the otherwise resistant DS-MCF-7 cells (Figure 5i, right panel), whereas MCF-7 cells with ROS quencher NAC reduced the amount of $\mathrm{ROS}$ generated in cisplatin-treated MCF-7 cells (Figure 5i, left panel) but also imposed resistance in them (Figure 5i, right panel). These findings further ascertained the importance of 'amount' of ROS in deciding the fate of tumors. In corroboration with the aforementioned findings, activation of the $\mathrm{ATM}-\mathrm{NF}_{\kappa} \mathrm{B}$ chemoresistance pathway in resistant DS-MCF-7 cells (Figure 5j) and dominant apoptotic response via JNK activation in sensitive MCF-7 cells were witnessed (Figure $5 \mathrm{j}$ ).

Translating in vitro results in the resistant tumor allograft-bearing mouse model. To validate the in vitro results in an in vivo mouse model, we transplanted cisplatinsensitive (CS-EAC) and cisplatin-resistant (CR-EAC) Ehrlich's ascites carcinoma cells ${ }^{22}$ into the peritoneal cavity of recipient Balb/c mice. These EACs were also resistant to structurally and functionally unrelated drugs such as doxorubicin and vinblastine. ${ }^{23}$ After 2 weeks when extensive EAC liquid tumor formation could be observed, cisplatin treatment was started. Whereas treatment with cisplatin led to marked decrease in abdominal perimeter, tumor volume 
a

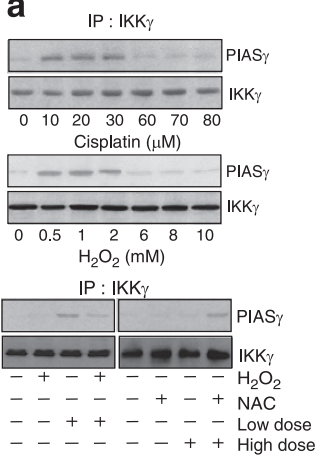

b

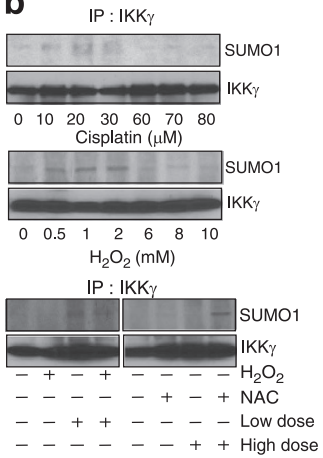

C $\quad$ IP : PIAS $\gamma$

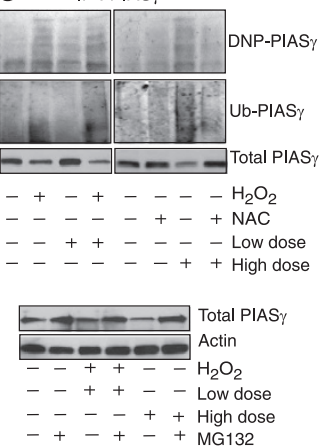

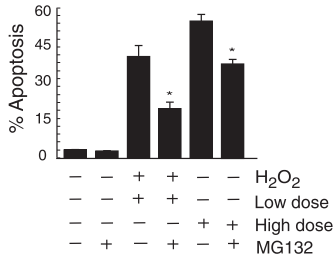

d

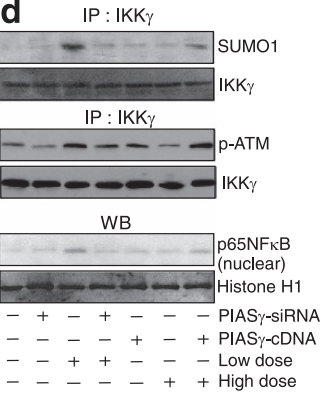

e

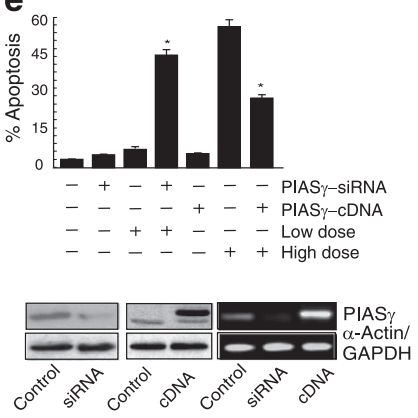

f

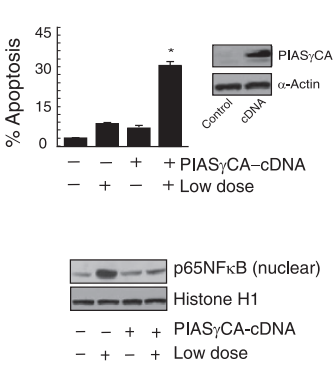

$g$

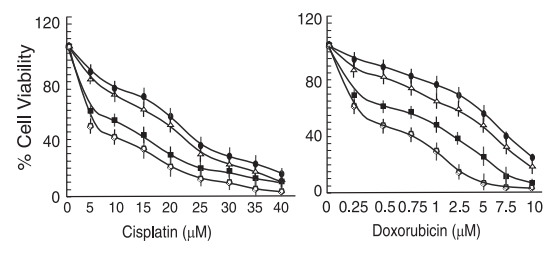

- MCF-7 DS-MCF-7 $\triangle$ HT-29 7 Colo-205 h

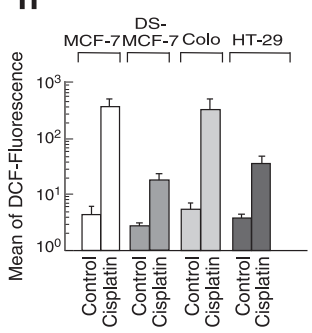

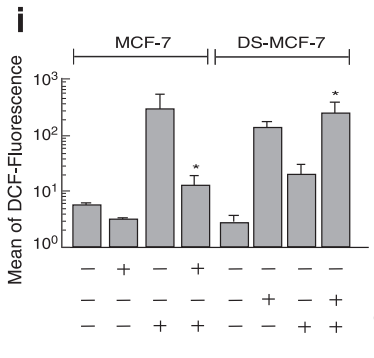

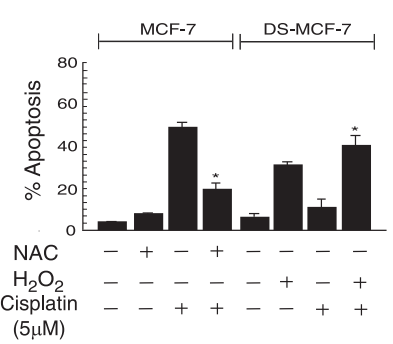

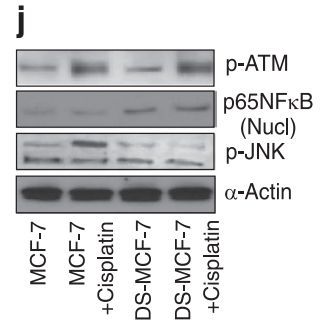

Figure 5 Degradation of PIAS $\gamma$ at high ROS during genotoxic stress interrupts the ATM/IKK $\gamma$ interaction with subsequent activation of NF $\kappa B$ in resistant cells. ROS dependency of (a) PIAS $\gamma / \mathrm{IKK} \gamma$ interaction and (b) IKK $\gamma$ sumoylation were analyzed in $\mathrm{A} 549$ cells treated with $\mathrm{H}_{2} \mathrm{O}_{2}(4 \mathrm{mM}, 1 \mathrm{~h}) / \mathrm{NAC}(40 \mathrm{mM}, 12 \mathrm{~h})$ prior to cisplatin, by co-immunoprecipitation and Western blotting. (c) PIAS $\gamma$ immunoprecipitates from $\mathrm{H}_{2} \mathrm{O}_{2} / \mathrm{NAC}$ pre-incubated cisplatin-treated A549 cells were probed with anti-DNP and anti-ubiquitin antibodies to determine the levels of PIAS $\gamma$ oxidation and degradation (upper left panel). Total PIAS $\gamma$ level was determined in MG132 pre-incubated and cisplatin- $/ \mathrm{H}_{2} \mathrm{O}_{2}$-treated A549 cells (lower panel). Flow cytometric analyses of the same experimental set further determined percent apoptosis by Annexin-V-/7-AAD-positivity (right panel). (d) Co-immunoprecipitation to assess the IKK $\gamma$ sumoylation, IKK $\gamma$-pATM interaction and western blotting analysis to determine p65NF $\kappa \mathrm{B}$ nuclear translocation in untransfected/PIAS $\gamma$-siRNA-/PIAS $\gamma$-CDNA-transfected cells in presence and absence of cisplatin. (e) Flow cytometric analyses of the same experimental set for assessing percent apoptosis by Annexin-V-/7-AAD-positivity (upper panel). The effectiveness of PIAS $\gamma$ genetic modifications was validated by both western blot analysis and RT-PCR (lower panel). (f) Percent apoptosis was scored in A549 cells transfected with the catalytically inactive PIAS $\gamma$ CDNA (PIAS $\gamma$ CA-cDNA)/WT-A549 cells using Annexin-V-/7-AAD flow cytometric assay (upper panel). The effectiveness of PIAS $\gamma C A$ transfections was validated by western blot analysis (inset). The western blotting technique was employed to examine $\mathrm{p} 65 \mathrm{NF} \kappa \mathrm{B}$ nuclear translocation in un-transfected/PIAS $\gamma \mathrm{CA}-\mathrm{cDNA}$-transfected cells in presence and absence of cisplatin (lower panel). (g) Percent viability of different cancer cells treated with dose ranges of cisplatin and doxorubicin was scored by using trypan blue dye exclusion assay. (h) Untreated-/Cisplatin $(5 \mu \mathrm{M})$-treated cancer cells were assessed flow cytometrically by monitoring the increase in DCF-DA fluorescence for amount of ROS produced. (i) $\mathrm{H}_{2} \mathrm{O}_{2}$-pre-treated-DS-MCF-7 and NAC-pre-treated-MCF-7 cells were estimated flow cytometrically by measuring DCFH-DA fluorescence (left panel) and Annexin-V-/7-AAD-positivity (right panel). (j) Western blot analysis for the levels of p-ATM, nuclear p65 and p-JNK in un-/cisplatin ( $5 \mu \mathrm{M})$ treated MCF-7 and DS-MCF-7 cells. $\alpha$-Actin and histone H1 were used as internal controls. Values are mean \pm S.E.M. of five independent experiments in each case. ${ }^{*} P<0.01$ when compared with respective un-transfected/normal sets

and viable cell count of CS-EAC-implanted mice (Figures $6 \mathrm{a}$ and b), CR-EACs manifested increase in abdominal perimeter, tumor volume and viable tumor cell count suggesting ineffectiveness of cisplatin treatment (Figures $6 a$ and b). In addition, in cisplatin-treated sets, CS-EACs showed remarkable apoptosis when compared with CR-EACs (Figure 6c). Validating our in vitro results, unlike in sensitive cells in which cisplatin-induced significant elevation in ROS levels (Figure $6 \mathrm{~d}$ ) was paralleled by a dominant apoptotic response via p-JNK and caspase-3 activations (Figure 6e), cisplatin failed to significantly elevate ROS levels in resistant cells (Figure 6d), thereby facilitating the PIAS $\gamma$-dependent ATM-NF $\kappa$ B chemoresistance pathway (Figure 6e).

To re-validate the above-mentioned results, we took two approaches. In the first approach, sensitive EAC cells were stably transfected with an empty vector $(E A C-V)$ or a vector-containing WT PIAS $\gamma$ gene (EAC-P), 
a

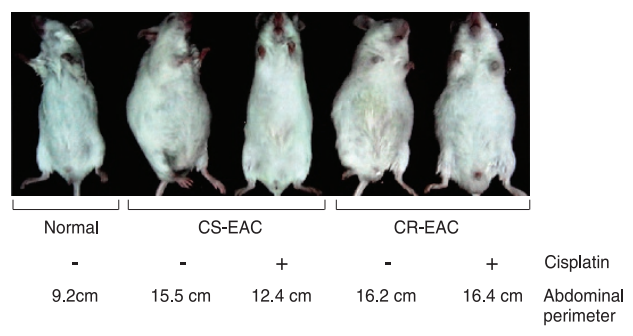

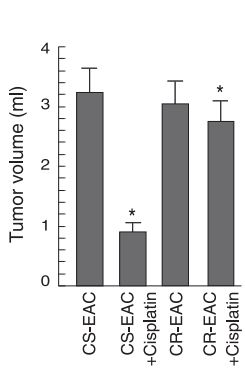

b

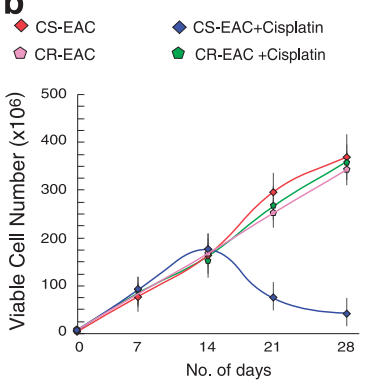

C

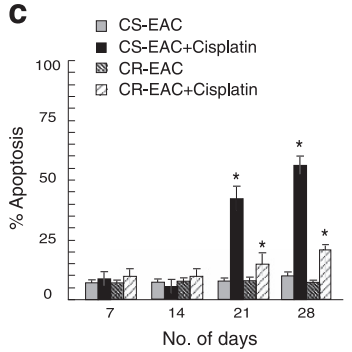

d $\quad$ CS-EAC

- CS-EAC

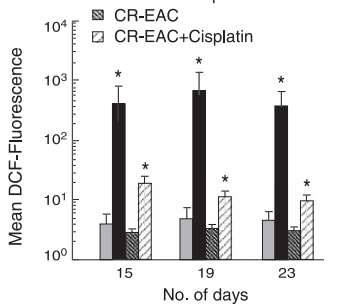

e

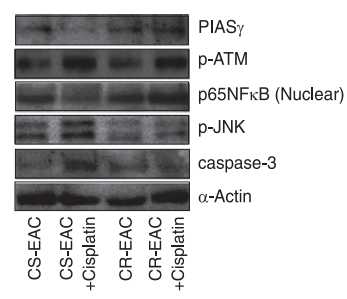

Figure 6 Translating in vitro results in mice model bearing multi-drug-resistant tumor allograft. BALB/c mice injected with CS-EACs and CR-EACs were treated with $3 \mathrm{mg} / \mathrm{kg}$ cisplatin at day 15, 19 and 23 and killed on 7, 14, 21 and 28 days of tumor inoculation. They were then scored for (a) abdominal perimeter (left panel) and tumor volume number (right panel), (b) viable tumor cell number and (c) percentage apoptosis. (d) EAC cells were aseptically removed from control and cisplatin-treated CS-EAC and CR-EAC-bearing mice within $2 \mathrm{~h}$ of drug administration and subjected to flow cytometric determination of cellular ROS. (e) From the same experimental set, a portion of cells was subjected to western blot analysis of PIAS $\gamma$, p-ATM, nuclear p65, p-JNK and caspase-3. $\alpha$-actin was used as an internal control. Values are mean \pm S.E.M. of five independent experiments in each case. ${ }^{*} P<0.01$ when compared with respective untreated/normal sets

respectively (Figure 7a). Stable expression of WT PIAS $\gamma$ in EAC-P cells enhanced chemoresistance of these otherwise sensitive EAC cells to cisplatin compared with EAC-V cells in vitro (Figure 7a). Next, these EAC-V or EAC-P cells were transplanted intra-peritoneally in BALB/c mice. Allografts derived from EAC-V cells furnished significant reduction in abdominal perimeter, tumor volume and viable tumor count compared with EAC-P after cisplatin treatment (Figures 7b and c). Furthermore, EAC-P-transplanted tumors furnished lesser apoptotic cells than EAC-V-derived tumors in cisplatin-treated groups (Figure 7d). ROS level was not only significantly high in EAC-V than EAC-P upon cisplatin treatment (Figure 7e) but also was positively correlated with percent apoptosis of tumor cells (Figure $7 \mathrm{~d}$ ). In the second approach, CR-EACs were engineered to express PIAS $\gamma$ CA clone. Consistent with our in vitro findings, mice bearing the CR-EAC-PIAS $\gamma$ CA tumor showed significantly reduced tumor volume when compared with the CR-EAC-PIAS $\gamma$ WT tumors upon cisplatin treatment (Figures $7 f$ and $g$ ). All these outcomes not only validated the in vitro data but also raised the possibility of the presence of a positive feed-back loop in resistant cancer cells where the PIAS $\gamma$-induced ATM-NF $\kappa$ B pathway created an antioxidative microenvironment ${ }^{24}$ that, failing to sufficiently degrade PIAS $\gamma$, re-contributed to hypoxia-mediated chemoresistance and continued the cycle.

In gist, our in vitro and in vivo findings together establish a critical combinatorial function of cellular ROS and PIAS $\gamma$ in cross-connecting the ATM-NF $\kappa$ B and ATM-JNK pathways, thereby ultimately deciding the fate of resistant cancer cells to genotoxic chemotherapy (Figure 8).

\section{Discussion}

This report strengthened the importance of PIAS $\gamma$-mediated IKK $\gamma$ sumoylation that channelizes genotoxic drug-induced ATM signals toward the resistance pathway at low ROS, whereas the high ROS-mediated PIAS $\gamma$ degradation served as a pivot in driving ATM-dependent chemosensitization of drug-resistant cancer cells.

In our experimental system, as the amount of genotoxic stress-induced ROS was correlated with ATM-mediated apoptosis in otherwise resistant cancer cells, it appeared logical to draw a hypothesis that beyond a threshold level intracellular ROS functioned as the master regulator in switching over ATM's response from resistance to apoptosis. Supporting our hypothesis, few studies have described a role for ROS in various aspects of ATM function, suggesting that ATM could be a sensor of perturbations in redox homeostasis triggering the activation of various signal transduction pathways. ${ }^{25-27}$ Certain studies suggesting that loss of ATM may correlate with resistance to DNA-damaging chemotherapy and poor patient survival ${ }^{28,29}$ questioned the contribution of ATM in cellular response to anticancer therapies. The general perception is that the extent of DNA damage or the downstream factor(s) may be the major issue in this decision. Support comes from the role played by tumor suppressor p53 in repairing DNA damage in response to the mild stress, whereas high doses of the same DNA-damaging agents result in p53dependent apoptosis in an ATM-dependent manner. ${ }^{30-32}$ However, it is yet not known as to how the extent of ROS produced during DNA damage regulates ATM function, if any, and the molecular mechanisms underlying this process. 
a

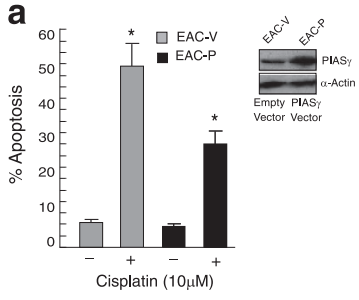

e

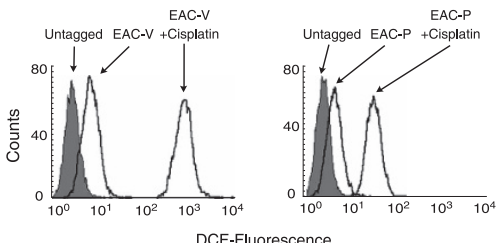

b

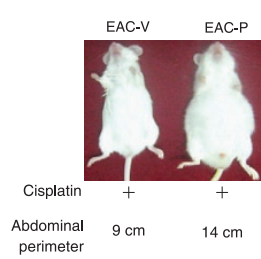

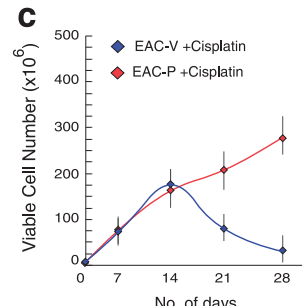

No. of days d

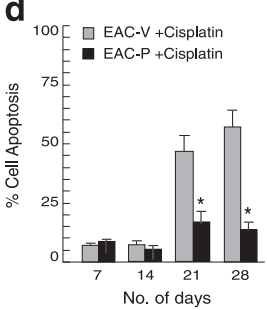

Figure 7 PIAS $\gamma$ cDNA-transfected sensitive tumors manifested low ROS up on cisplatin treatment to demonstrate chemoresistance response. (a) Sensitive EAC cells were transfected with empty vector (EAC-V) or vector containing PIAS $\gamma$ WT-cDNA (EAC-P) and scored for their sensitivity to cisplatin $(10 \mu \mathrm{M})$. The effectiveness of PIAS $\gamma$ modification was confirmed by Western blot analysis (inset). (b) Mice implanted with the EAC-V or EAC-P cells were evaluated for change in abdominal perimeter (left panel) and tumor volume (right panel) after treatment with cisplatin. Graphical representation of (c) viable cell count, and (d) percent apoptosis of the EAC-V and EAC-P cells after cisplatin treatment. (e) Histogram overlay (left panel) and graphical representation (right panel) depicting ROS in cisplatin-treated EAC-V or EAC-P tumors. (f) CR-EAC were transfected with the vector containing PIAS $\gamma$ CA-cDNA (catalytically inactive form of PIAS $\gamma$ ) and scored for their sensitivity to cisplatin $(10 \mu \mathrm{M})$. (g) Mice implanted with either the CR-EAC cells or the PIAS $\gamma$ CA-CDNA-expressing CR-EAC cells were evaluated for change in tumor volume (left panel) and viable cell number (right panel) after treatment with cisplatin. $\alpha$-actin was used as internal control. Values are mean \pm S.E.M. of five independent experiments in each case. ${ }^{*} P<0.01$ when compared with respective untreated/normal sets. Values are mean \pm S.E.M. of five independent experiments in each case

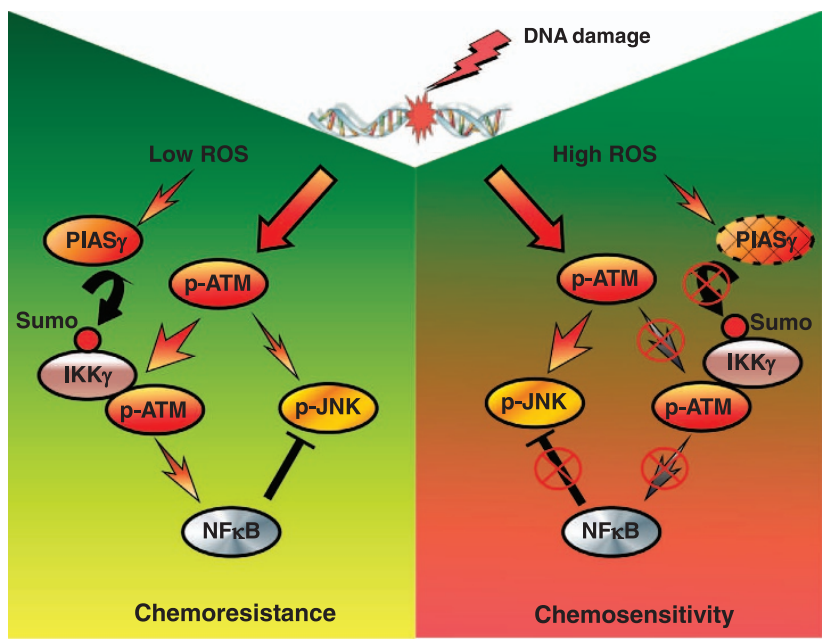

Figure 8 Schematic illustration depicts the role of ROS-PIAS $\gamma$ cross-talk in differentially regulating DNA damage responses towards ATM-mediated chemoresistance or chemosensitization

Our studies showed that at low ROS environment, which was generated by low dose of genotoxic drug, ATM activates the p65NF $\kappa \mathrm{B}$-mediated resistance pathway. However, inactivating $\mathrm{p} 65 \mathrm{NF} \kappa \mathrm{B}$ directly by gene silencing or indirectly by biochemical increment of ROS restored the ATM-dependent JNK death cascade. This observation is consistent with recent studies where elevated $\mathrm{p} 65 \mathrm{NF} \kappa \mathrm{B}$ activity hampers tumor cell killing by genotoxic conditions, and even a transient exposure to small doses of chemotherapy induces resistance by the activation of $\mathrm{p} 65 \mathrm{NF} \kappa \mathrm{B} .{ }^{33-37}$ However, unlike high ROS where
ATM specifically induced JNK phosphorylation and apoptosis, at low ROS, an ATM's response was open for both NF $\kappa$ B and JNK activation as ATM knockdown at low ROS only partially sensitized drug-resistant cells to killing by genotoxic chemotherapy, thereby leaving room for ATM's contribution also to apoptosis at low ROS, which was overpowered by p65NF $\kappa \mathrm{B}$. In fact, our subsequent search identified p65NF $\kappa \mathrm{B}$ induced MKP1 as the masking factor for JNK-1 during low dose treatment, thereby justifying our findings that, at high ROS when p65NF $\kappa$ B was inhibited, why ATM signal gets channelized toward the JNK-1 apoptotic pathway. In gist, despite the molecular complexity of DNA damage response networks, a simple stratification based solely on the combined status of ROS and its cross talk with ATM might help determine the response to genotoxic chemotherapy.

Shifting of ATM signal from p65NF $\kappa$ B to JNK-1 next raises the question as to why high $\mathrm{ROS}$ resulted in $\mathrm{p} 65 \mathrm{NF}_{\kappa} \mathrm{B}$ inhibition. The first reason comes from the fact that, with ATM failing to bind IKK $\gamma$ at high ROS, the chances of PIAS $\gamma$ not sumoylating IKK $\gamma$ at high ROS became favorable. Further exploration into this signaling event revealed that, in contrast to mild genotoxic stress, high ROS generated by severe DNA damage oxidized E3 SUMO ligase, PIAS $\gamma$, and hindered the interaction between PIAS $\gamma-\mathrm{IKK} \gamma$. Degradation of PIAS $\gamma$ upon extensive oxidation, therefore, appeared to be the major cause behind negative regulation of the ATM-IKK $\gamma-\mathrm{NF} \kappa \mathrm{B}$ signaling during conditions of high ROS following DNA damage. Consistently, PARP-1-, PIAS $\gamma$ - or IKK $\gamma$ deficient mouse embryonic fibroblast was strongly and equivalently sensitized to IR-induced apoptosis. ${ }^{38}$ Interestingly, mice lacking PARP, an important component of the PARP-PIAS $\gamma$ IKK $\gamma$-ATM signalosome complex, revealed an extreme sensitivity and a high genomic instability to genotoxic agents. ${ }^{38}$ 
Supporting our findings, Luciani et al. have shown that PIAS $\gamma$ induced Transglutaminase 2 (TG2) sumoylation, which contributed to $\mathrm{p}_{65 \mathrm{NF}} \kappa \mathrm{B}$-mediated inflammation at ROS levels similar to that which favored PIAS $\gamma$-mediated IKK $\gamma$ sumoylation and p65NF $\kappa \mathrm{B}$ activation in our study. ${ }^{39}$ In harmony with earlier reports where sumoylation is ROS-dependent, ${ }^{40,41}$ the novelty of our finding lies in the fact that ROS though initially favorable, beyond a certain threshold becomes inhibitory for PIAS $\gamma-\mathrm{IKK} \gamma$ interaction. Originally described as STAT interacting protein, PIAS $\gamma$ is characterized by a RING-like motif with characteristic spacings of cysteines required for SUMOE3 ligase activity. ${ }^{42}$ Consistently, a recent study conducted by Mabb et al. ${ }^{43}$ showed that overexpression of a catalytically inactive mutant PIAS $\gamma$ (PIAS $\gamma$ CA with the catalytic Cys 342 and Cys 347 mutated to alanine) inhibited sumoylation of IKK $\gamma$ and $\mathrm{p}_{65 \mathrm{NF}} \mathrm{B}$ activation. Concomitantly, a comparative analysis of the structures of the kinase domains of IKKs and related kinases indicates that oxidation of Cys-179 in either $\mathrm{IKK} \alpha$ or IKK $\beta$ would lead to its inhibition and hence p $65 \mathrm{NF}_{\kappa} \mathrm{B}$ inactivation, suggesting that cysteine residues are at increasing risk of ROS-mediated oxidation. ${ }^{44,45}$ Oxidation is one of the chief causes of protein damage, subject to which proteins undergo extensive degradation. ${ }^{46}$ On the basis of above cited literature we further propose that redox sensitive modification/ oxidation of PIAS $\gamma$ catalytic cysteine residues and its subsequent degradation at high dose cisplatin might be the reason for inhibiting the PIAS $\gamma-\mathrm{IKK} \gamma$ interaction and hence IKK $\gamma$ sumoylation. Of note, other roles for PIAS $\gamma$ in regulating $\mathrm{p} 65 \mathrm{NF}_{\kappa} \mathrm{B}$ function have also been observed. In a study conducted by Albor et al., ${ }^{47}$ PIAS $\gamma$ inhibited transcriptional activity of $\mathrm{NF}_{\kappa} \mathrm{B}$ in mouse keratinocyte cell line in response to combination of UV and TNF $\alpha$. However, in our study though PIAS $\gamma$ was inevitable for nuclear translocation of $\mathrm{p}^{2} 5 \mathrm{NF}_{\kappa \mathrm{B}}$ at low ROS, the p65NF $\kappa$ B-dependent MKP1 transcription remained unaffected by PIAS $\gamma$. Perhaps similar ROS levels were found to inhibit trans-repressing activity of PIAS $\gamma$ by favoring TG2-mediated histone deacetylase 3 ubiquitination. ${ }^{39}$

In summary, it is acknowledged that cancer cells in advanced stage tumors frequently exhibit high oxidative stress and the upregulation of antioxidant capacity in adaptation to this intrinsic oxidative stress confers drug resistance in these cells. Abrogation of such drug-resistant mechanisms by redox modulation by a combinatorial therapy of exogenous ROS-generating agents with conventional chemotherapy might be an effective strategy for eliminating these otherwise 'drug-resistant' cancer cells. The present study providing new insights into the role of ROS in deciding the 'life or death' choices of chemorefractory tumors opens up an avenue for designing 'redox modulation strategies' for chemosensitization of resistant tumors.

\footnotetext{
Materials and Methods

Cell culture and treatments. The human non-small cell lung cancer cells, A549, H1299, H460, human breast cancer cells, MCF-7, and human colon cancer cells, Colo-205, HT-29, were obtained from National Center for Cell Science, India. Drug surviving-MCF-7 cells (DS-MCF-7) were drug-resistant subclone of MCF-7 cells. Cells were routinely maintained in Dulbecco's modified Eagle's medium supplemented with $10 \%$ fetal bovine serum at $37^{\circ} \mathrm{C}$ in a humidified incubator containing $5 \% \mathrm{CO}_{2}$. Cells were treated with different concentrations of cisplatin, doxorubicin, etoposide and $\mathrm{H}_{2} \mathrm{O}_{2}$ (Sigma, St. Louis, MO, USA) for different time points to select the optimum resistance or apoptotic dose. To evaluate the
}

involvement of p38 mitogen-activated protein kinase (p38MAPK), JNK and ATM, cells were pre-treated with a specific p38MAPK inhibitor (SB203580; $10 \mu \mathrm{M}$, Calbiochem, Gibbstown, NJ, USA), JNK inhibitor (SP600125; $10 \mu \mathrm{M}$, Calbiochem) $90 \mathrm{~min}$ before treatment and with an ATM inhibitor (Wortmanin; $20 \mu \mathrm{M}$ and KU55933; $10 \mu \mathrm{M}$, Calbiochem) $30 \mathrm{~min}$ before drug treatment. To neutralize druginduced oxidative stress, cells were pre-treated with $\mathrm{N}$-acetyl cysteine (NAC; $40 \mathrm{mM}$, Sigma) for $1 \mathrm{~h}$ before drug treatment. To validate that PIAS $\gamma$ oxidation leads to ubiquitin-mediated degradation, cells were pre-exposed with a proteasome inhibitor (MG132; $10 \mu \mathrm{M}$, Calbiochem) for $2 \mathrm{~h}$ before drug treatment.

Flow cytometry and confocal imaging. For the determination of cell death, cells were stained with 7-AAD and Annexin-V-FITC and analyzed on a flow cytometer (FACS Calibur, Beckton Dickinson, Mount View, CA, USA). For the assessment of cellular ROS, cultured cells or sensitive as well as resistant EAC cells, aseptically drawn within $2 \mathrm{~h}$ of drug treatment from the peritoneal cavity of tumor-bearing mice, were incubated for $20 \mathrm{~min}$ at $37^{\circ} \mathrm{C}$ in the dark with $10 \mu \mathrm{M}$ of dichlorofluorescindiacetate (DCFH-DA, Sigma). ${ }^{48}$ DCF fluorescence was measured flow cytometrically (Beckton Dickinson FACScan) and subjected to analysis using Cell Quest 3.2 (Beckton Dickinson) software. The probe was excited at $488 \mathrm{~nm}$, and emission was measured through a $530 \mathrm{~nm}$ band-pass filter.

For confocal microscopy, cells were grown on sterile glass coverslips at $37^{\circ} \mathrm{C}$ for $24 \mathrm{~h}$. Cells after treatment were washed briefly with PBS and fixed with $4 \%$ formaldehyde for $20 \mathrm{~min}$ at $37^{\circ} \mathrm{C}$. Thereafter, cells were blocked for $2 \mathrm{~h}$ in a blocking buffer $(10 \%$ BSA in PBS) and then additionally incubated for another hour in PBS with $1.5 \%$ BSA containing anti-p65NF $\kappa$ B, p-ATM and IKK $\gamma$ (Santa Cruz, Santa Cruz, CA, USA). After washing in PBS, cells were incubated with FITC- or rhodamine-conjugated secondary antibodies in PBS with $1.5 \%$ BSA for $45 \mathrm{~min}$ at $37^{\circ} \mathrm{C}$ in the dark. DAPI or PI was used for nuclear staining. Coverslips were washed with PBS and mounted on microscopy glass slides with $90 \%$ glycerol in PBS. Images were acquired using a confocal microscope (Carl Zeiss, Jena, Germany).

Co-immunoprecipitation and immunoblotting. For western blot analysis, the cell lysates or the particular fractions (nuclear/cytoplasmic) were separated by SDS-PAGE, transferred to nitrocellulose membrane and visualized by chemiluminescence. ${ }^{49-52}$ For the determination of direct interaction between two proteins, the co-immunoprecipitation technique was employed. The immunopurified proteins were then detected by western blot using a specific antibody (Santa Cruz). Equal protein loading was confirmed with an $\alpha$ actin/Histone H1 antibody (Santa Cruz).

Plasmid, siRNA, transfections and RT-PCR. The cDNA encoding p65NF $\kappa \mathrm{B}, \mathrm{DN}-\mathrm{IKK} \alpha, \mathrm{DN}-\mathrm{IKK} \beta$ and $\mathrm{I}_{\kappa} \mathrm{B} \alpha-32 \mathrm{~A} / 36 \mathrm{~A}$ ( $\left.\right|_{\kappa} \mathrm{B} \alpha$ super-repressor $\left(I_{\kappa} \mathrm{B} \alpha-\right.$ $\mathrm{SR}$ ), kind gift from Dr. J Didonato, The Cleveland Clinic), were subcloned into pcDNA3.1 plasmids. The plasmid encoding PIAS $\gamma$ and PIAS $\gamma$ CA-CDNA (the catalytic active residues of PIAS $\gamma$-Cys 342 and Cys 347 are mutated to alanine) and IKKy mutant clones was a generous gift from Dr. Shigeki Miyamoto, Wisconsin Institutes Medical Research. pcDNA3.1 (+) Flag-His-ATMwt-cDNA (plasmid 31985) was procured from Addgene (Cambridge, MA, USA). An siRNAresistant ATM-cDNA allele was constructed from ATM-cDNA with three base changes in the siRNA-targeting site (nucleotides 606-615 of ATM, $5^{\prime}$ CGGAGCTGATTGTAACAACA-3' to $5^{\prime}$-CGGAGCCGATTGCAATAACA-3'), which altered codon usage but did not change the amino acid sequence. The sequence of the specific ATM-siRNA used were 5'-GUUGCUACAAUCAGCUCCG-3', Antisense $5^{\prime}$-GGAGCUGAUUGUAGCA AC- $3^{\prime}$. The plasmids were introduced separately into cells using lipofectamine-2000 (Invitrogen, Carlsbard, CA, USA). Isolation of stably expressing clones was obtained by limiting dilution and selection with G418 sulfate (Cellgro, Kansas City, MO) at a concentration of $1 \mu \mathrm{g} / \mathrm{ml}$. Cells were transfected with 300 pmole of ATM/JNK-/p38MAPK-/PIAS $\gamma$-/MKP1-/MKK4-/ control-ds-si-RNA and lipofectamine-2000 separately for $12 \mathrm{~h}$. The mRNA and protein levels were determined by RT-PCR and western blotting. Two micrograms of total RNA, extracted with TRIzol reagent (Invitrogen), was reverse transcribed and then subjected to PCR with enzymes and reagents of the RTplusPCR system (Eppendorf, Hamburg, Germany) using a GeneAmp PCR system 2720 (Applied Biosystems, Foster City, CA, USA). ${ }^{52}$ Primers for MKP1 were $5^{\prime}$-CCTGACAGCGC GGAATCT-3' and 5'-GATTTCCACCGGGCCAC-3'; JNK were 5'-GCCTGTCGCA CGTGATTGA-3' and 5'-CGTCTTCGTTCGCACTGTTG-3'; p38MAPK were 5'-GA AGAGCCTGACCTACGAT-3' and 5'-ACTGCCAAGGAGCATCTA-3'; PIAS $\gamma$ were $5^{\prime}$-CTTTAATATGCTGGATGAGCTG-3' ${ }^{\prime}$ and $5^{\prime}$-CTCCTTGACCAGTGCCTTGCAC-3' 
and glyceraldehyde 3-phosphate dehydrogenase (internal standard) were 5'-CAGAACATCATCCCTGCCT CT-3' and 5'-GCTTGACAAAGTGGTCGTTGAG-3'.

Animal and tumor model. BALB/c mice (NCLAS, Hyderabad, India) weighing 20-25 g were maintained in temperature-controlled room with light-dark cycle. Mice were intra-peritoneally (i.p) injected with $1 \times 10^{5}$ exponentially grown cisplatin-sensitive or resistant Ehrlich's ascites carcinoma (EAC) cells. ${ }^{22,23}$ EAC-P and EAC-V were stable cell lines generated from EAC-sensitive cells upon transfection with PIASyWT-CDNA or empty vector and subsequently selected with G418. Similarly, resistant EAC-PIASyCA was generated from resistant EAC cells transfected with PIASyCA clone. For in vivo experiments, 14 days post tumor inoculation, mice were treated with a cumulative dose of $9 \mathrm{mg} / \mathrm{kg}$ body weight cisplatin where $3 \mathrm{mg} / \mathrm{kg}$ body weight was i.p injected on day 15, 19 and 21. At regular time interval, the abdominal periphery was measured and then the animals were killed to analyze tumor volume, tumor cell number and tumor cell apoptosis. The EAC cells were isolated from the peritoneal cavity of tumor-bearing mice (control or treated). Two to three milliliters of sterile PBS was injected into the peritoneal cavity of the mice, and the peritoneal fluid containing the tumor cells was withdrawn, collected in sterile Petri dishes and incubated at $37^{\circ} \mathrm{C}$ for $2 \mathrm{~h}$. The cells of macrophage lineage adhered to the bottom of the Petri dishes. The nonadherent population was aspirated out gently and washed repeatedly with PBS. EAC cells were then separated from other non-adherent contaminating cells by FACS (fluorescence-activated cell sorter). More than $98 \%$ of this separated cell population was CD3/CD14/CD19/CD56 negative as was determined by a flow cytometer. Moreover, these cells were morphologically characterized as EAC by Wright staining and viability was assessed to be $>95 \%$ by Trypan Blue dye exclusion. A portion of tumor cells was subjected to western blot determination of PIAS $\gamma, p-A T M, p 65 N F \kappa B$, p-JNK and caspase-3. Each experimental set consisted of 10 animals. All animal experiments were performed following 'Principles of laboratory animal care' (NIH publication No. 85-23, revised in 1985) as well as Indian laws on 'Protection of Animals' under the prevision of authorized investigators.

Statistical analysis. Values are shown as standard error of mean (S.E.M.). Data were analyzed and, when appropriate, significance of the differences between mean values was determined by a Student's $t$ test. Results were considered significant at $P<0.01$.

\section{Conflict of Interest}

The authors declare no conflict of interest.

Acknowledgements. We thank Ms. R Sarkar for editing the manuscript We also thank Mr. U Ghosh and Mr. R Dutta for technical help. This work was supported by the grants from DST, CSIR and UGC, Government of India.

1. Li Y, Tan BB, Zhao Q, Fan LQ, Liu Y, Hao YJ et al. Tumor chemosensitivity is correlated with expression of multidrug resistance associated factors in variously differentiated gastric carcinoma tissues. Hepato-gastroenterol 2013; 60: 213-216.

2. Connolly EC, Saunier EF, Quigley D, Luu MT, Sapio A, Hann B et al. Outgrowth of drug-resistant carcinomas expressing markers of tumor aggression after long-term T $\beta R \mathrm{R} / \mathrm{ll}$ kinase inhibition with LY2109761. Cancer Res 2011; 71: 2339-2349.

3. Gridelli C, Rossi A, Maione P, Ferrara ML, Castaldo V, Sacco PC. Vaccines for the treatment of non-small cell lung cancer: a renewed anticancer. Oncologist 2009; 14 909-920.

4. Norbury CJ, Zhivotovsky B. DNA damage-induced apoptosis. Oncogene 2004; 23 2797-2808.

5. Yang J, Xu ZP, Huang Y, Hamrick HE, Duerksen-Hughes PJ, Yu YN. ATM and ATR: sensing DNA damage. World J Gastroenterol 2004; 10: 155-160.

6. Huang Y, Sen T, Nagpal J, Upadhyay S, Trink B, Ratovitski E et al. ATM kinase is a master switch for the Delta Np63 alpha phosphorylation/degradation inhuman head and neck squamous cell carcinoma cells upon DNA damage. Cell Cycle 2008; 7: 2846-2855.

7. Tian B, Yang Q, Mao Z. Phosphorylation of ATM by Cdk5 mediates DNA damage signaling and regulates neuronal death. Nat Cell Biol 2009; 11: 211-218.

8. Jiang $\mathrm{H}$, Reinhardt $\mathrm{HC}$, Bartkova J, Tommiska J, Blomqvist $\mathrm{C}$, Nevanlinna $\mathrm{H}$ et al. The combined status of ATM and p53 link tumor development with therapeutic response. Genes Dev 2009; 23: 1895-1909.

9. Chun HH, Gatti RA. Ataxia-telangiectasia an evolving phenotype. DNA Repair 2004; 3 : 1187-1196.
10. Tribius S, Pidel A, Casper D. ATM protein expression correlates with radioresistance in primary glioblastoma cells in culture. Int J Radiat Oncol Biol Phys 2001; 50: 511-523.

11. Wu ZH, Shi Y, Tibbetts RS, Miyamoto S. Molecular linkage between the kinase ATM and NF-kappaB signaling in response to genotoxic stimuli. Science 2006; 311: 1141-1146.

12. Sawayama Y, Miyazaki Y, Ando K, Horio K, Tsutsumi C, Imanishi D et al. Expression of myeloperoxidase enhances the chemosensitivity of leukemia cells through the generation of reactive oxygen species and the nitration of protein. Leukemia 2009; 22: 956-964.

13. Verbon EH, Post JA, Boonstra J. The influence of reactive oxygen species on cell cycle progression in mammalian cells. Gene 2012; 511: 1-6.

14. Zhou Y, Hileman EO, Plunkett W, Keating MJ, Huang P. Free radical stress in chronic lymphocytic leukemia cells and its role in cellular sensitivity to ROS-generating anticancer agents. Blood 2003; 101: 4098-4104.

15. Wartenberg M, Gronczynska S, Bekhite MM, Saric T, Niedermeier W, Hescheler J et al. Regulation of the multidrug resistance transporter P-glycoprotein in multicellular tumor spheroids by hypoxia-inducible factor (HIF-1) and reactive oxygen species. FASEB J 2003; 17: $503-505$

16. Chiou JF, Tai CJ, Wang YH, Liu TZ, Jen YM, Shiau CY. Sorafenib induces preferential apoptotic killing of a drug- and radio-resistant Hep G2 cells through a mitochondriadependent oxidative stress mechanism. Cancer Biol Ther 2009; 8: 1904-1913.

17. Takahashi A, Ohtani N, Yamakoshi $\mathrm{K}$, lida S, Tahara H, Nakayama KI et al. Mitogenic signalling and the p16INK4a-Rb pathway cooperate to enforce irreversible cellular senescence. Nat Cell Biol 2006; 8: 1291-1297.

18. Zhang H, Kong $\mathrm{X}$, Kang J, Su J, Li Y, Zhong J et al. Oxidative stress induces parallel autophagy and mitochondria dysfunction in human glioma U251 cells. Toxicol Sci 2009; 110: $376-388$

19. Lee GH, Kim HK, Chae SW, Kim DS, Ha KC, Cuddy M et al. Bax inhibitor-1 regulates endoplasmic reticulum stress-associated reactive oxygen species and heme oxygenase-1 expression. J Biol Chem 2007; 282: 21618-21628.

20. Harte MT, Gorski JJ, Savage KI, Purcell JW, Barros EM, Burn PM et al. NF-кB is a critical mediator of BRCA1-induced chemoresistance. Oncogene 2013; e-pub ahead of print 25 February 2013; doi:10.1038/onc.2013.10.

21. Vicent S, Garayoa M, López-Picazo JM, Lozano MD, Toledo G, Thunnissen FB et al. Mitogen-activated protein kinase phosphatase-1 is overexpressed in non-small cell lung cancer and is an independent predictor of outcome in patients. Clin Cancer Res 2004; 10: 3639-3649.

22. Sen GS, Mohanty S, Hossain DMS, Bhattacharyya S, Banerjee S, Chakraborty J et al. Curcumin enhances the efficacy of chemotherapy by tailoring p65NFKB-p300 cross-talk in favor of p53-p300 in breast cancer. J Biol Chem 2011; 286: 42232-42247.

23. Choudhuri SK, Chatteriee A. Reversal of resistance against doxorubicin by a newly developed compound, oxalylbis(N-phenyl)hydroxamic acid in vitro. Anticancer Drugs 1998; 9: 825-832.

24. Papa S, Bubici C, Zazzeroni F, Pham CG, Kuntzen C, Knabb JR et al. The NFkappaBmediated control of the JNK cascade in the antagonism of programmed cell death in health and disease. Cell Death Differ 2006; 13: 712-729.

25. Rotman G, Shiloh Y. Ataxia-telangiectasia: is ATM a sensor of oxidative damage and stress. Bioessays 1997; 19: 911-917.

26. Kurz EU, Douglas P, Lees-Miller SP. Doxorubicin activates ATM-dependent phosphorylation of multiple downstream targets in part through the generation of reactive oxygen species. J Biol Chem 2004; 279: 53272-53281.

27. Alexander A, Cai SL, Kim J, Nanez A, Sahin M, MacLean KH et al. ATM signals to TSC2 in the cytoplasm to regulate mTORC1 in response to ROS. Proc Natl Acad Sci USA 2010; 107: 4153-4158.

28. Mancini M, Petta S, lacobucci I, Salvestrini V, Barbieri E, Santucci MA. Zinc-finger transcription factor slug contributes to the survival advantage of chronic myeloid leukemia cells. Cell Signal 2010; 22: 1247-1253.

29. Kurrey NK, Jalgaonkar SP, Joglekar AV, Ghanate AD, Chaskar PD, Doiphode RY et al. Snail and slug mediate radioresistance and chemoresistance by antagonizing p53-mediated apoptosis and acquiring a stem-like phenotype in ovarian cancer cells. Stem Cell 2009; 27: 2059-2068.

30. Haidar MA, Kantarjian H, Manshouri T, Chang CY, O'Brien S, Freireich E et al. ATM gene deletion in patients with adult acute lymphoblastic leukemia. Cancer 2000; 88: 1057-1062.

31. Ripollés L, Ortega M, Ortuño F, González A, Losada J, Ojanguren J et al. Genetic abnormalities and clinical outcome in chronic lymphocytic leukemia. Cancer Genet Cytogenet 2006; 171: 57-64.

32. Offer H, Erez N, Zurer I, Tang X, Milyavsky M, Goldfinger $\mathrm{N}$ et al. The onset of p53-dependent DNA repair or apoptosis is determined by the level of accumulated damaged DNA. Carcinogenesis 2002; 23: 1025-1032.

33. Mauro C, Zazzeroni F, Papa S, Bubici C, Franzoso G. The NF-kappaB transcription factor pathway as a therapeutic target in cancer: methods for detection of NF-kappaB activity. Methods Mol Biol 2009; 512: 169-207.

34. Guo G, Yan-Sanders Y, Lyn-Cook BD, Wang T, Tamae D, Ogi J et al. Manganese superoxide dismutase-mediated gene expression in radiation-induced adaptive responses. Mol Cell Biol 2003; 23: 2362-2378.

35. Kozakai N, Kikuchi E, Hasegawa M, Suzuki E, Ide H, Miyajima A et al. Enhancement of radiosensitivity by a unique novel NF- $\mathrm{KB}$ inhibitor, $\mathrm{DHMEQ}$, in prostate cancer. $\mathrm{Br} J$ Cancer 2012; 107: 652-657. 
36. Berger R, Jennewein C, Marschall V, Karl S, Cristofanon S, Wagner $L$ et al. NF- $\kappa B$ is required for Smac mimetic-mediated sensitization of glioblastoma cells for $\gamma$-irradiationinduced apoptosis. Mol Cancer Ther 2011; 10: 1867-1875.

37. Stilmann M, Hinz M, Arslan S C, Zimmer A, Schreiber V, Scheidereit CA et al. A nuclear poly (ADP-ribose)-dependent signalosome confers DNA damage-induced lkappaB kinase activation. Mol Cell 2009; 36: 365-378.

38. Murcia JM, Niedergang C, Trucco C, Ricoul M, Dutrillaux B, Mark M et al. Requirement of poly (ADP-ribose) polymerase in recovery from DNA damage in mice and in cells. Proc Nat Acad Sci. USA 1997; 94: 7303-7307.

39. Villella VR, Vasaturo A, Giardino I, Raia V, Pettoello-Mantovani M et al. SUMOylation of tissue transglutaminase as link between oxidative stress and inflammation. J Immunol 2009; 183: 2775-2784.

40. Xu Z, Lam L S, Lam LH, Chau SF, Ng TB, Au SW. Molecular basis of the redox regulation of SUMO proteases: a protective mechanism of intermolecular disulfide linkage against irreversible sulfhydryl oxidation. FASEB J 2008; 22: 127-137.

41. Bossis G, Melchior F. Regulation of SUMOylation by reversible oxidation of SUMO conjugating enzymes. Mol Cell 2006; 21: 349-357.

42. Takahashi Y, Kahyo T, Toh-E A, Yasuda H, Kikuchi Y. Yeast Ull1/Siz1 is a novel SUMO1/ Smt3 ligase for septin components and functions as an adaptor between conjugating enzyme and substrates. J Biol Chem 2001; 276: 48973-48977.

43. Mabb AM, Wuerzberger-Davis SM, Miyamoto S. PIASy mediates NEMO sumoylation and NF-kappaB activation in response to genotoxic stress. Nat Cell Biol 2006; 8: 986-993.

44. Jaspers I, Zhang W, Fraser A, Samet JM, Reed W. Hydrogen peroxide has opposing effects on IKK activity and IkappaBalpha breakdown in airway epithelial cells. Am J Respir Cell Mol Biol 2001; 24: 769-777.

45. Michiels $\mathrm{C}$, Minet E, Mottet D, Raes M. Regulation of gene expression by oxygen: NF-kappaB and HIF-1, two extremes. Free Radic Biol Med 2002; 33: 1231-1242.

46. Yamanaka K, Ishikawa H, Megumi Y, Tokunaga F, Kanie M, Rouault TA et al. Identification of the ubiquitin-protein ligase that recognizes oxidized IRP2. Nat Cell Biol 2003; 5: 336-340.
47. Albor A, El-Hizawi S, Horn EJ, Laederich M, Frosk P, Wrogemann K et al. The interaction of Piasy with Trim32, an E3-ubiquitin ligase mutated in limb-girdle muscular dystrophy type $2 \mathrm{H}$, promotes Piasy degradation and regulates UVB-induced keratinocyte apoptosis through NFkappaB. J Biol Chem 2006; 281: 25850-25866.

48. Adhikary A, Mohanty S, Lahiry L, Hossain DMS, Chakraborty S, Das T. Theaflavins retard human breast cancer cell migration by inhibiting NF-kappaB via p53-ROS cross-talk. FEBS Lett 2010; 584: 7-14.

49. Das T, Sa G, Hilston C, Kudo D, Rayman P, Biswas K et al. GM1 and TNF, overexpressed in renal cell carcinoma, synergize to induce T cell apoptosis. Cancer Res 2008; 68: 2014-2023.

50. Das T, Sa G, Paszkiewicz-Kozik E, Hilston C, Molto L, Rayman P et al. Renal cell carcinoma tumors induce $T$ cell apoptosis through receptor-dependent and receptor-independent pathways. J Immunol 2008; 180: 4687-4696.

51. Chakraborty J, Banerjee S, Ray P, Hossain DMS, Bhattacharyya S, Adhikary A et al. Gain of cellular adaptation due to prolonged p53 impairment leads to functional switchover from p53 to p73 during DNA damage in acute myeloid leukemia cells. J Biol Chem 2010; 285: 33104-33112.

52. Bhattacharyya S, Mandal D, Sen GS, Pal S, Banerjee S, Lahiry L et al. Tumor-induced oxidative stress perturbs nuclear factor-kappaB activity-augmenting tumor necrosis factor-alpha-mediated T-cell death: protection by curcumin. Cancer Res 2007; 67: 362-370.

cc)(1)(2) Cell Death and Disease is an open-access journal ca licensed under a Creative Commons Attribution-NonCommercialShareAlike 3.0 Unported License. To view a copy of this license, visit http://creativecommons.org/licenses/by-nc-sa/3.0/

Supplementary Information accompanies this paper on Cell Death and Disease website (http://www.nature.com/cddis) 